\title{
The local hormonal environment and related biomarkers in the normal breast
}

\author{
$S$ A Khan, D Bhandare and R T Chatterton $J r^{1,2}$
}

\author{
Department of Surgery, ${ }^{1}$ Department of Obstetrics and Gynecology and ${ }^{2}$ Department of Physiology, Robert H Lurie Comprehensive \\ Cancer Center, Feinberg School of Medicine of Northwestern University, Chicago, Illinois, USA \\ (Requests for offprints should be addressed to S A Khan, Lynn Sage Breast Center, 675 North St Clair, Galter 13-174, \\ Chicago, Illinois 60611, USA; Email: skhan@nmh.org)
}

\begin{abstract}
Recent developments in breast epithelial sampling techniques (nipple fluid aspiration, ductal lavage, and random fine needle aspiration) provide new opportunities for the acquisition of hormonal and cellular biomarker data in asymptomatic women, and thereby the possibility of developing a unified vision of how the hormonal environment of the breast may interact with the cellular expression of proteins, and with other evolving candidate markers of breast cancer risk. The purpose of this review is to integrate available information regarding cellular and breast fluid biomarkers of hormone action on the breast, to identify candidate biomarkers for studies of breast cancer risk and prevention. These include the estrogen receptors $\alpha$ and $\beta$, markers of proliferative and apoptotic response, and protein markers of estrogen action in breast cells and nipple fluid. Studies of breast hormone levels in nipple aspiration fluid (NAF) show that estrone sulphate is present in large quantities in the normal breast, while the differences in serum ovarian steroids that are seen in preand postmenopausal women are blunted in NAF. The variability of several estradiol precursors in NAF over time is relatively small, a useful attribute of potential biomarkers of breast cancer risk, particularly if they are reversible with intervention in Phase 2 prevention trials. These studies are already providing new insights into the hormonal etiology of breast cancer, and should lead to the identification of robust, reversible biomarkers for use in breast cancer prevention studies.
\end{abstract}

Endocrine-Related Cancer (2005) 12 497-510

\section{Introduction}

The past decade has seen a proliferation of information regarding the endocrinology and intracrinology of the normal breast, and parallel information regarding the expression of hormone-related biomarker expression in the breast. However, relatively few attempts have been made to synthesize these two areas into an understanding of how local hormonal metabolism influences potential biomarkers such as proliferation, apoptosis and hormone receptor expression. With the availability of breast epithelial and ductal fluid sampling techniques such as nipple fluid aspiration, ductal lavage (DL) and random fine needle aspiration (rFNA), there is now an opportunity to measure both the hormone levels of breast ductal fluid, and the cellular response in the form of proliferation, apoptosis and the expression of estrogen-response proteins. This review addresses the available literature on cellular biomarkers of hormone-related breast cancer risk in breast tissue samples, and developing areas using newer sampling techniques, which promise to increase our understanding of normal breast biology, and point to candidate biomarkers for use in prevention studies.

\section{The current paradigm}

The normal non-lactating breast is subject to cyclical changes in response to ovarian stimulation with either estrogen alone during anovulatory cycles, or estrogen plus progesterone during ovulatory cycles. These hormones increase breast epithelial cell proliferation, with progesterone having a synergistic/additive effect during ovulatory cycles. The withdrawal of hormones 
with the onset of a new ovarian cycle causes a wave of apoptosis, eliminating defective cells and maintaining the population balance of the epithelium. Repeated waves of proliferation, however, lead to an accumulation of genetic defects, with the eventual emergence of a transformed cell, leading to the clonal evolution of malignancy (Cohen \& Ellwein 1991, King 1993, Pike et al. 1993). Therefore, factors that increase availability of hormones, augment the proliferative response of the epithelium to hormonal stimulation, or interfere with apoptotic elimination of defective cells, will increase breast cancer risk. Factors which decrease hormone availability, blunt proliferative response, or aid apoptotic elimination will protect against breast cancer.

This paradigm is consistent with present evidence: length of reproductive life and number of ovulatory cycles increase breast cancer risk (Hankinson \& Hunter 2002) and breast epithelial proliferation is highest in the luteal phase (Ferguson \& Anderson 1981). Exposure to high postmenopausal serum estrogen levels contributes to increased risk of breast cancer (Trichopoulos et al. 1983, Hankinson et al. 1998). However, there are gaps; no long-term studies have related high proliferative rates of breast epithelium to increased risk of breast cancer. The value of proliferation as a surrogate endpoint in the breast has not been demonstrated, and the role of apoptosis (whether increased or decreased in the high-risk breast) is poorly understood. The importance of local breast hormone levels with regard to breast cancer risk has not been studied.

\section{Studies of serum hormone levels and hormone metabolism relevant to breast cancer}

Studies of circulating sex steroid levels and breast cancer risk have necessarily focused on postmenopausal women, since the menstrual cycle variations of premenopausal women have been a significant barrier to such investigations. Among postmenopausal women, correlations between serum estrogen levels and breast cancer risk have been observed in almost all of the larger studies, with relative risk estimates ranging from 1 to 4 for several of the estrogenic hormones studied. In particular, the results of a nested case-control analysis of the Nurses Health Cohort showed the strongest effects for estrone sulfate (ES), dehydroepiandrosterone sulfate (DHEAS) and estradiol, with relative risks of $4.34,4.15$ and 3.53 respectively (Hankinson et al. 1998). Several other case-control studies have shown that serum estradiol approached significant trends within quartiles or quintiles (Toniolo et al. 1995, Kabuto et al. 2000). An overview analysis of studies published until 1997 concluded that serum estradiol levels in women who develop breast cancer are about $15 \%$ higher than in those who do not (Thomas et al. 1997).

Among premenopausal women, serum hormone levels were measured at specified intervals during the menstrual cycle in a case-control study of 169 breast cancer subjects; no significant relationships were found with estradiol in any part of the menstrual cycle (Sturgeon et al. 2004). A possible solution to the problem of fluctuating hormone levels in premenopausal women is the measurement of estradiol and progesterone in salivary samples, since saliva can be collected by the subjects at home and stored without refrigeration for subsequent analysis once a full month of samples has been collected. The data can be analyzed to give an integrated level over the entire menstrual cycle. In addition, salivary steroids are thought to reflect levels of unbound, bioavailable serum steroids, and may be more relevant to studies of breast hormonal exposure than serum or plasma steroid levels.

\section{Measurements of hormones in nipple aspiration fluid (NAF)}

With the development of therapeutic approaches based on inhibition of extra-ovarian estradiol synthesis, and data regarding local synthesis of estrogen in breast tumors, there is increasing interest in the idea that local hormone levels in the breast may have more relevance to promotion of breast cancer than serum hormone levels. The analysis of estrogens in NAF has been performed by several investigators in the past (Rose et al. 1986, Ernster et al. 1987, Petrakis et al. 1987), and we have performed several studies of hormones and hormone response proteins in the soluble fraction of NAF (Chatterton et al. 2000, 2003, 2004, 2005). The results from these studies are discussed below.

\section{Relationship of hormones in NAF to concentrations of the hormones in serum}

In several studies of serum and NAF estradiol and progesterone, the correlations between serum and NAF hormone levels have been variable. Our first and smallest study $(n=10)$ showed a correlation between serum and NAF estradiol of 0.55 , with a mean mid-luteal phase serum estradiol of $292 \pm 36 \mathrm{pmol} / 1$ and simultaneous NAF estradiol of $1478 \pm 324 \mathrm{pmol} / 1$, (Chatterton et al. 2003). However, subsequent studies, using the same methodology have not shown a 
Table 1 Summary of literature on serum and NAF hormone levels

\begin{tabular}{|c|c|c|c|c|}
\hline \multirow[t]{2}{*}{ Reference (number subjects) } & \multicolumn{2}{|c|}{ Estradiol (pmol/L \pm SE) } & \multicolumn{2}{|c|}{ Estrone (pmol/L $\pm \mathrm{SE})$} \\
\hline & Serum & NAF & Serum & NAF \\
\hline \multicolumn{5}{|l|}{ Ernster et al. 1987} \\
\hline Premenopausal (76) & 354 & 3166 & 284 & 4822 \\
\hline Postmenopausal (11) & 56 & 3101 & 123 & 4433 \\
\hline \multicolumn{5}{|l|}{ Petrakis et al. 1987} \\
\hline Never pregnant (23) & 378 & 536 & 281 & 5276 \\
\hline Gravid-nulliparous (20) & 362 & 4598 & 275 & 6574 \\
\hline Parous (36) & 433 & 1832 & 323 & 2838 \\
\hline \multicolumn{5}{|l|}{ Rose et al. 1986} \\
\hline Premenopausal (24) & $323 \pm 70$ & $2882 \pm 727$ & $240 \pm 63$ & $3722 \pm 912$ \\
\hline \multicolumn{5}{|l|}{ Chatterton* et al. 2003} \\
\hline & \multicolumn{2}{|c|}{ Estradiol (pmol/L) } & \multicolumn{2}{|c|}{ Estrone sulfate (nmol/L) } \\
\hline & Serum & NAF & Serum & NAF \\
\hline Follicular (10) & $169 \pm 18$ & $1200 \pm 167$ & & $1418 \pm 457$ \\
\hline Luteal (10) & $292 \pm 36$ & $1478 \pm 324$ & & $1971 \pm 507$ \\
\hline \multicolumn{5}{|l|}{ Chatterton* et al. 2005} \\
\hline Premenopausal (47) & $328(304-352)$ & $316(271-368)$ & $12.8(11.2-14.5)$ & $2000(1646-2431)$ \\
\hline OC users (13) & $94.7(74.9-120.1)$ & $108(64-179)$ & $2.7(2.3-3.2)$ & $203(117-346)$ \\
\hline Postmenopausal (18) & $52.5(46.3-59.5)$ & $120(11-179)$ & $1.8(1.6-2.1)$ & $1088(826-1434)$ \\
\hline HRT users (7) & 131 (86.6-198.3) & $2181(1660-2868)$ & $5.3(3.5-8.2)$ & 537 (274-1057) \\
\hline
\end{tabular}

${ }^{*}$ Estradiol levels in NAF were assayed after extraction and purification. The purification procedure, solvent partition between $0.4 \mathrm{~N} \mathrm{NaOH}$ and isooctane, resulted in values 8-fold lower than those obtained after extraction alone (Chatterton et al. 2004). Data of other investigators were obtained without purification. Reproduced from Chatterton et al. 2004 with permission from Cancer Epidemiology, Biomarkers \& Prevention.

significant correlation between serum and NAF estradiol. In a second study of 47 women the serum estradiol concentration at mid-luteal phase was similar $(356 \pm 65.4 \mathrm{pmol} / \mathrm{l})$, whereas in NAF it was lower $(484 \pm 28 \mathrm{pmol} / \mathrm{l})($ Chatterton et al. 2004). The latter value corresponds closely to concentrations of estradiol in tissue of premenopausal women when the tissue concentration is expressed in $\mathrm{pmol} / \mathrm{g}$ (Thijssen et al. 1986, Blankenstein et al. 1999). There was no correlation between concentrations of DHEAS and ES in serum and those in NAF. Correlations between serum and NAF hormone levels have not generally been published in older studies, although Ernster et al. (1987) reported a correlation of 0.1 between serum and NAF estradiol, and 0.14 between serum and NAF estrone, both of which were not statistically significant.

Progesterone, which has not been measured previously in NAF, averaged $207.2 \pm 3.8 \mathrm{ng} / \mathrm{ml}$ in our first study, and serum averaged $15.5 \pm 2.2 \mathrm{ng} / \mathrm{ml}$. In the second study NAF progesterone averaged $91.5 \pm$ $9.9 \mathrm{ng} / \mathrm{ml}$ and serum averaged $15.5 \pm 0.3 \mathrm{ng} / \mathrm{ml}$. The correlations between serum and NAF in the two studies were 0.27 and 0.20 respectively. Thus, accumulation of progesterone relative to serum levels was also significantly lower in the second group of subjects, who were also more physically active, suggesting an effect of exercise on uptake or retention of estrogen and progesterone by the breast.

In a subsequent study, using similar methods, we have examined the effects of oral contraceptives (OCs) and hormone replacement therapy (HRT) on NAF and serum hormone levels (Chatterton et al. 2005). The correlations between serum and NAF hormones are generally poor but mean NAF hormone levels reflected the overall trends in mean hormone levels seen in the serum. Thus, estradiol levels were lower in both serum and NAF of OC users compared with controls, and higher in serum and NAF of HRT users compared with controls. However, in postmenopausal HRT users, the differences in NAF estradiol were more marked than those in serum estradiol: NAF estradiol of women on HRT was 18-fold higher than postmenopausal control women, whereas serum estradiol was only 2.5 -fold higher. From these data, it appears that changes in serum hormones are reflected in NAF, but only after a matter of days.

Our results are in general agreement with the older literature in this area (summarized in Table 1) in that NAF hormone levels are higher than serum levels, and the decline in serum estradiol seen with menopause is 
not seen to the same extent in NAF (Chatterton et al. 2005). There have been few investigations of NAF hormone levels in relation to breast cancer risk. In a study of women with clinically normal breasts, those with benign disease, and those with breast cancer, Ernster et al. (1987) saw no significant differences in mean values across groups. Petrakis et al. (1987) have compared the breast fluid estradiol and estrone levels between nulliparous, parous and lactating women, and have reported that parous and lactating women had significantly lower levels than those who were nulliparous. And Rose et al. (1986) have compared NAF hormone levels in American and Finnish women, and found those in Finnish women (who have a lower breast cancer risk) to be lower. Previously reported estradiol levels in NAF, measured without purification, were 2 to 8 times higher than those reported by Chatterton et al. 2003, 2004 (Rose et al. 1986, Ernster et al. 1987). This difference was shown to be potentially attributable to cross-reactivity of the antiserum with ES and DHEAS, which are present in $10^{4}$ and $10^{5}$ times greater concentrations respectively than estradiol in NAF (Chatterton et al. 2004). Purification of the samples was required for elimination of the cross-reacting steroids.

\section{Relationship between estradiol precursors and estradiol in NAF}

Data from the second group described above include measurement of potential androgen precursors that may be metabolized to estradiol within the breast. With estradiol as the outcome measure, and accounting for the other variables such as breast and time of sampling by covariance techniques, the $\beta$-estimate for DHEA was $0.153 \pm 0.060(P=0.017)$ (Chatterton et al. 2004). Thus, even in premenopausal subjects androgen precursors were significantly related to the levels of estradiol in the breast.

ES is of interest because of its potential as a precursor of estradiol and its high concentration in NAF. ES within the breast was also related to NAF estradiol; the $\beta$-estimate was $0.201 \pm 0.066(P=0.004)$. Since ES circulates in relatively high concentration, and is concentrated in breast fluid, it may also be an important source of estradiol in the breast, as proposed by others (Pasqualini et al. 1996, 1997, Purohit et al. 1999).

We have found evidence of conversion of ES to estrone in breast parenchymal cells from grossly normal breast tissue of women undergoing excision of benign lumps (Chatterton et al. 2003). Despite the low concentration of ES in the cells, it was converted linearly within a 1000 -fold concentration range of up to $10 \mu \mathrm{M}$ to estrone by intact cells, having a mean halftime of conversion of $628 \mathrm{~min} / 10^{6}$ cells. Upon comparing the rate of metabolism of ES in homogenized cells to that in intact cells, we found that homogenized cells had a conversion half-time that was about $50 \%$ shorter, suggesting that the plasma membrane is a barrier to conversion to estrone. These results are consistent with the reported site of the sulfatase in the microsomal fraction of the cells (Hernandez-Guzman et al. 2001). However, it is also possible that hydrolysis of ES occurs without entering the cell. Willemsen et al. (1988) have shown that estrogen sulfatase activity also resides on the plasma membrane. In this case, the high levels of estrone sulfatase that enter the lumen of the ductal tree, apparently by an active transport process (Pizzagalli et al. 2003), may be hydrolyzed to estrone before entering the epithelial cells. Thus estrogen sulfatase activity would make ES a ready source of estrone to the mammary parenchyma.

\section{Relationship between estrogens in breast fluid and estrogen response proteins}

Estradiol promotes the synthesis of both epidermal growth factor (EGF) and cathepsin D; both are present in measurable concentrations in NAF, and may indicate whether the concentrations of estradiol in NAF are biologically meaningful. In the second group of 47 subjects mentioned above, both estradiol and ES were significantly related to NAF EGF levels; $\beta$-estimates were $0.082 \pm 0.035(P=0.024)$ and $0.216 \pm 0.035 \quad(P=0.0001)$ respectively (Chatterton et al. 2004). Similarly, cathepsin D showed a significant relationship to estradiol and ES, with $\beta$-estimates of $0.28(P=0.015)$ and $0.32(P=0.002)$. Similar estimates of the relationships between serum estradiol and EGF and cathepsin D were not statistically significant in our study. NAF pS2 has also been shown to increase in postmenopausal women starting HRT, and decrease in premenopausal women starting goserelin therapy (Harding et al. 2000). Overall, it seems reasonable to assume that NAF estrogen concentration provides a better estimate of biologically active estrogen in the breast than do serum levels of estradiol. The fact that ES had higher correlations with these products may relate to the fact that its concentration is very high in NAF and easily and accurately measured. On the other hand, levels of estradiol in NAF were often at the lower limit of sensitivity of the method and for approximately $30 \%$ of the samples were not detected by the immunoassay method. 
Table 2 Mean concentration of analytes in nipple aspirate fluid from premenopausal women with correlations between breasts and over time

\begin{tabular}{lcccr}
\hline Analyte & $\begin{array}{c}\text { Number of } \\
\text { Subjects } \\
\text { (Samples) }\end{array}$ & $\begin{array}{c}\text { Concentration } \\
\text { (mean } \pm \text { SE) }\end{array}$ & $\begin{array}{c}\text { Right vs Left } \\
\text { Breast } \\
\text { Correlations* }\end{array}$ & $\begin{array}{c}\text { Correlations } \\
\text { over 15 months } \\
\text { per breast* }\end{array}$ \\
\hline Protein & $47(271)$ & $74.4 \pm 2.1 \mathrm{mg} / \mathrm{ml}$ & & \\
Estradiol & $31(188)$ & $435 \pm 27 \mathrm{pmol} / \mathrm{L}$ & $0.61(0.34,0.78)$ & $0.65(0.43,0.80)$ \\
Estrone sulfate & $43(284)$ & $3.74 \pm 0.26 \mu \mathrm{mol} / \mathrm{L}$ & $0.84(0.73,0.91)$ & $0.93(0.88,0.96)$ \\
DHEAS** & $45(292)$ & $75.1 \pm 6.7 \mu \mathrm{mol} / \mathrm{L}$ & $0.67(0.47,0.81)$ & $0.88(0.80,0.93)$ \\
DHEA & $42(269)$ & $56.0 \pm 6.1 \mathrm{nmol} / \mathrm{L}$ & $0.65(0.43,0.79)$ & $0.71(0.53,0.83)$ \\
Androstenedione & $24(147)$ & $6.0 \pm 0.6 \mathrm{nmol} / \mathrm{L}$ & $0.71(0.47,0.85)$ & $0.77(0.57,0.88)$ \\
Progesterone & $43(288)$ & $291 \pm 29 \mathrm{nmol} / \mathrm{L}$ & $0.71(0.53,0.83)$ & $0.76(0.61,0.86)$ \\
Cathepsin D & $47(292)$ & $3.42 \pm 0.38 \mu \mathrm{g} / \mathrm{ml}$ & $0.68(0.47,0.81)$ & $0.74(0.58,0.85)$ \\
EGF & $47(299)$ & $424 \pm 12 \mathrm{ng} / \mathrm{mg}$ & $0.57(0.33,0.74)$ & $0.71(0.54,0.83)$ \\
IL-6 & $45(291)$ & $1.74 \pm 0.21 \mathrm{ng} / \mathrm{ml}$ & $0.73(0.53,0.85)$ & $0.64(0.42,0.79)$ \\
\hline
\end{tabular}

${ }^{*}$ Correlations by the permutation method with $95 \% \mathrm{Cl}$.

** Measured after hydrolysis as DHEA.

Reproduced from Chatterton et al. 2004 with permission from Cancer Epidemiology, Biomarkers \& Prevention.

\section{Variability of NAF hormones over time}

In the group of 47 premenopausal women described above, we determined the stability of hormone measurements in NAF over a 15 month period. Saliva was collected daily throughout the baseline menstrual cycle and at 4, 12 and 15 months to ascertain menstrual cycle characteristics, and NAF and blood were collected approximately 7 days after ovulation. The analytic methods have been described previously (Chatterton et al. 2004). Concentrations of these analytes were compared between breasts of each woman and within breasts across the full 15 month period. The data are listed in Table 2, showing that the correlation over time is very good, and slightly greater than the correlation of simultaneous measurements between breasts.

The baseline and 15 month measurements are plotted against each other in Fig. 1. The concentrations of DHEAS and ES are particularly stable with correlations within women across 15 months of 0.93 and 0.88 respectively. This stability, which may be attributed in part to the precision of measurement of the high concentrations of these analytes found in $\mathrm{NAF}$, is encouraging in terms of the potential utility of these measures as surrogate endpoints for interventions which seek to lower local hormone levels in the breast. However, it is not clear at the moment whether or not sulfated estrone and DHEA in the breast are activated by steroid sulfatase, and to what extent they engender an estrogenic response in the breast epithelium. While NAF estradiol is in the same range or a few fold higher than concentrations in blood, the concentrations of DHEAS and ES are many-fold higher than blood levels. These concentrations cannot be attributed to high-affinity binding substances in NAF, and the high concentration appears to be limited to the breast fluid and not the epithelial cells (Chatterton et al. 2003). An anion transporter has been described which may be involved in the very high concentrations of steroid sulfates in breast fluid (Pizzagalli et al. 2003).

\section{Studies of kallikreins in NAF and relationship to hormones}

Sauter et al. (1996) have investigated the role of human kallikrein-3 (hK-3), also known as prostate specific antigen (PSA) in the breast as a marker for breast cancer risk. In a study of breast cancer patients and control women, an inverse relationship was seen between NAF PSA and the presence of epithelial proliferation and malignancy, particularly after the menopause. NAF PSA levels were associated with the mid-cycle rise of serum progesterone in seven of eight women but not with serum estradiol or gonadotropins, indicating that sampling must be done at the same stage of the menstrual cycle for consistent results (Sauter et al. 1998). A negative association was seen between NAF PSA and disease progression from Duct carcinoma in situ to metastatic breast cancer (Sauter et al. 2004a,b). Lower PSA concentrations have also been described in estrogen- and progesteronereceptor-negative tumors (Black et al. 2000). Additional $\mathrm{hK}-2,-6$ and -10 are expressed in the breast, but hK- 6 and $\mathrm{hK}-10$ were not associated with breast cancer. hK-2 exhibited patterns similar to that of pS2 but did not provide additional useful information (Sauter et al. 2004b). 

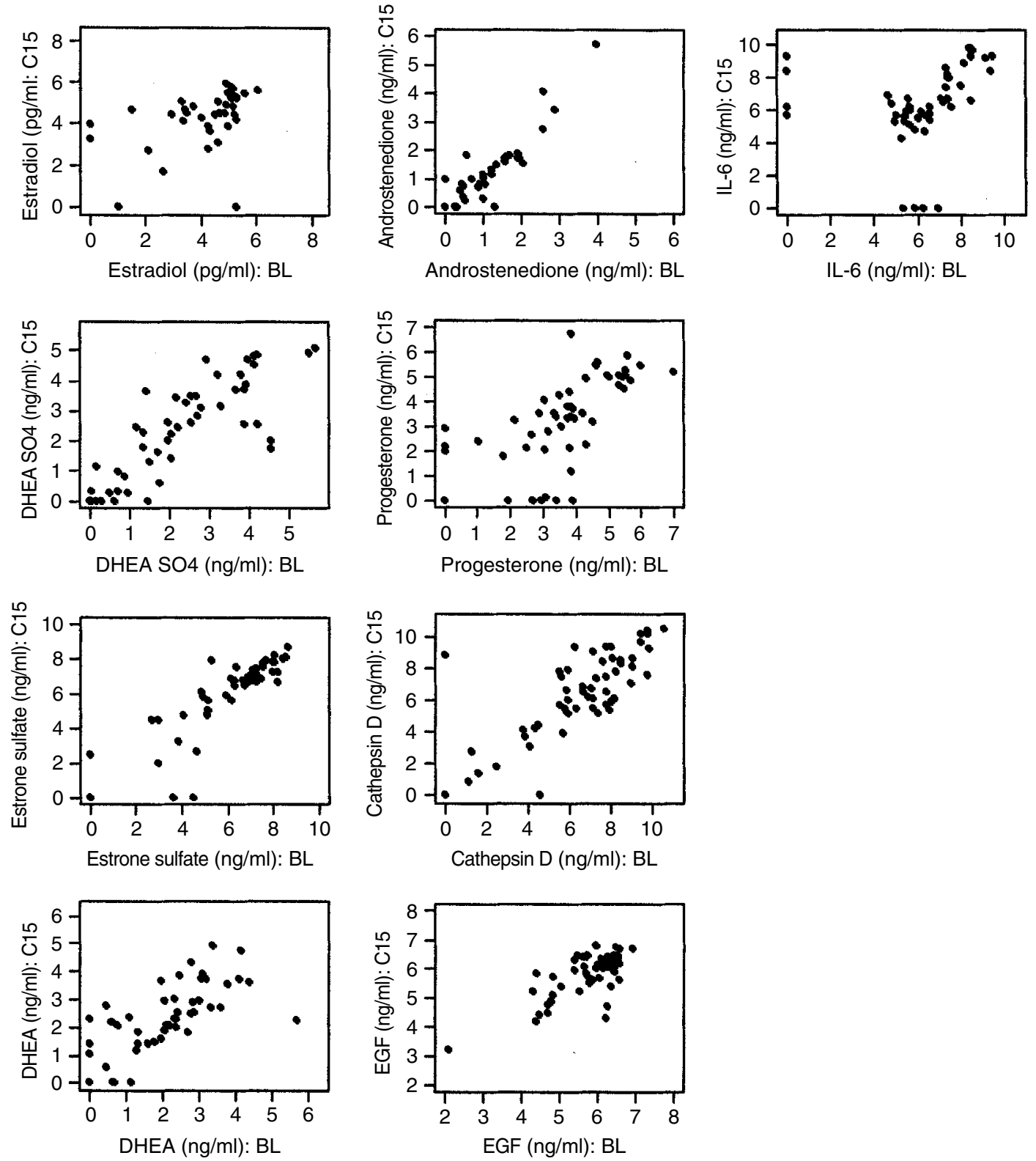

Figure 1 Distribution of log values for each analyte. Log values of the concentrations of each analyte in samples collected in the 15th month $(\mathrm{C} 15)$ are plotted against the corresponding log values in the baseline $(\mathrm{BL})$ samples. A correlation of 1.0 would be represented by a diagonal line from the lower left corner to the upper right of each plot. Plots of values from the 4th and 12th months vs the baseline samples are not shown for brevity, but the distributions were similar to those shown for the 15th month. That is, there was little increase in dispersion between the 4th and 15th months. Reproduced from Chatterton et al. 2004 with permission from Cancer Epidemiology, Biomarkers \& Prevention.

\section{Estrogen receptors in the normal breast}

\section{Breast tissue studies}

Estrogen receptor- $\alpha(E R \alpha)$ occupies a pivotal position in breast cancer biology, and has been the subject of intense study in malignant tumors. The earliest studies, using ligand-binding assays, showed little ER $\alpha$ expression in the normal breast (Feherty et al. 1971, Wittliff et al. 1971), but subsequent immunohistochemical (IHC) methods showed that a relatively small proportion (under 10\%) of luminal epithelial cells express ER $\alpha$ in the normal breast, whereas myoepithelial and stromal cells do not (Petersen et al. 1987). A number of IHC studies then followed, and established 
that $\mathrm{ER} \alpha$ expression is higher in the follicular than in the luteal phase of the menstrual cycle (Battersby et al. 1992), and that expression is higher in European than in non-European women (Ricketts et al. 1991). Since steroid receptor content appears to limit cellular response to steroids (Vanderbilt et al. 1987, Webb et al. 1992), we hypothesized that increased ER $\alpha$ expression in histologically normal breast epithelium may result in an augmented response to available estrogen, and may be a risk factor for breast cancer. In an initial study of 120 women, ER $\alpha$ expression in benign breast epithelium was measured using an IHC assay (Abbott ER-ICA) on frozen sections. ER $\alpha$ positive epithelium was found in a greater proportion of cases than controls ( 85 vs 55\%), with an adjusted odds ratio (OR) of $6.5,95 \%$ confidence interval (CI) 1.4-28.9 (Khan et al. 1994). This study was extended in order to examine the influence of breast cancer risk factors such as age at menarche, parity and menopause, and use of exogenous estrogens on breast epithelial ER $\alpha$ expression (Khan et al. 1999). Again, women with breast cancer expressed higher levels of $\mathrm{ER} \alpha$ than benign disease controls, but this was independent of known breast cancer risk factors, with the exception of alcohol use, where there was a trend towards higher ER $\alpha$ expression in premenopausal women who consumed more than three alcoholic drinks per week. We also observed that the breast epithelium of controls on HRT displayed significantly higher ER expression than that of controls not on HRT, an observation subsequently reproduced by Lawson et al. (2001), who showed that obesity also contributes to this higher expression.

The notion of increased ER $\alpha$ expression in the highrisk breast is supported by the consistency of high expression over time, demonstrated in a study of 28 women undergoing two separate breast biopsies at least 6 months apart (Khan et al. 2002). On categorizing the women into high and low expressers based on an ER labeling index (ER LI) value of 10, there was $86 \%$ concordance between the first and second samples. Among premenopausal women, the ability to predict the second ER LI from the first was improved significantly by the addition of the adjusted day of the menstrual cycle at the time of sampling, suggesting that a substantial part of the inter-sample variation in premenopausal women was explained by variation in the menstrual cycle day.

Ethnic variations suggest that groups at higher risk for breast cancer also have higher levels of ER expression: in a study comparing ER $\alpha$ expression in Australian women of European origin to that in Japanese women living in Japan, ER $\alpha$ expression was higher in the former, consistent with their higher breast cancer risk (Lawson et al. 1999). The same group of investigators then compared ER $\alpha$ expression in Japanese women in Hawaii with those in Japan, and found non-significantly higher levels in the Hawaiian Japanese, again in agreement with their higher breast cancer risk (Lawson et al. 2002). Finally, there are now several studies documenting the increase in the proportion of ER $\alpha$-expressing cells seen in proliferative breast lesions (Jacquemier et al. 1982, Shoker et al. 1999, 2000).

\section{Evidence of dysregulation of $E R \alpha$ expression relative to the hormonal environment}

Analysis of ER $\alpha$ expression by menstrual phase in our case-control study (Khan et al. 1998) revealed that the proportion of positive cells declined in luteal phase in controls, as seen in studies of naturally cycling women (Battersby et al. 1992). However, in women with cancer, this luteal phase decrease was not observed. There was a significant case-control difference in the ER LI in the 25-28 day interval $(P<0.03)$, and a significant trend towards increasing ORs through the menstrual cycle, from an OR of 1.3 in days $1-5$, compared with an OR of 4.4 in days $25-28(P<0.015)$. These data suggest that $\mathrm{ER} \alpha$ expression varies differently between cases and controls through the menstrual cycle. Since other lines of evidence suggest that an increase in ambient estradiol leads to downregulation of the receptor (Saceda et al. 1988, Ree et al. 1989), we then looked at ER $\alpha$ expression in normal breast epithelium relative to circulating estradiol levels. Here we found a significant negative correlation between serum estradiol and breast epithelial ER LI in the controls, but no correlation in women with breast cancer (Khan et al. 1999). These findings together suggest a disturbance of hormonal regulation of $E R \alpha$ expression in the breast epithelium of high-risk women.

\section{Do ER $\alpha$-expressing cells proliferate?}

Studies of dual labeling of breast epithelial sections for $E R \alpha$ and markers of proliferation have suggested that ER $\alpha$-expressing cells are distinct from proliferating cells, since markers of proliferation $\left(\mathrm{Ki}-67,\left[{ }^{3} \mathrm{H}\right]\right.$ thymidine) do not co-localize with $\mathrm{ER} \alpha$ (Clarke et al. 1997, Russo et al. 1999). Clarke et al. (1997) have suggested that ER $\alpha$-expressing cells are a distinct population and exert a paracrine influence on surrounding cells, which respond by proliferating. As the normal breast progresses through increasing degrees of neoplasia, the separation of the two compartments 
blurs, and co-localization of proliferation-related antigens and ER $\alpha$ is seen, suggesting a dysregulation of ER $\alpha$ expression. However, the number of co-localizing cells remains very small in malignancies, increasing from $0.03 \%$ in normal epithelium, to $1.3 \%$ in invasive cancer (Clarke et al. 1997). The alternative explanation (that $\mathrm{ER} \alpha$ expression is a cell cycle-related phenomenon) is addressed in a recent study of wild-type and ER $\beta$ - / - mice (Cheng et al. 2004). Oophorectomized mice were exposed to estradiol, an ER $\beta$ agonist, tamoxifen, or placebo. Bromodeoxyuridine (BrdU) was infused for labeling of S-phase cells, and mice were killed at 2 or $48 \mathrm{~h}$. This study confirmed that estradiol down-regulates ER $\alpha$ in mammary epithelial cells; colocalization of $E R \alpha$ and BrdU was not observed at $2 \mathrm{~h}$, but was seen at $48 \mathrm{~h}$, suggesting that ER $\alpha$-expressing cells do go on to divide, and do not represent two distinct cell populations.

\section{$E R \alpha$ data from studies using minimal sampling techniques}

More recent studies using methods such as rFNA also suggest that increased expression of ER $\alpha$ correlates with the probability of breast cancer development. In a comparison of 244 high-risk and 30 low-risk women, Fabian et al. (1997) found that ER $\alpha$ expression was significantly related to the presence of cytological atypia, and the subsequent development of cancer, particularly if a low threshold of positivity (1+) was used. These findings are consistent with our breast tissue studies, where the ability to discriminate cases from controls based on ER $\alpha$ expression in normal and non-proliferative epithelium is optimal with a low threshold of $\mathrm{ER} \alpha$ positivity (Khan et al. 1998). In a subsequent analysis of 480 women studied by rFNA, the same group found that ER $\alpha$ expression greater than $1+$ was the only biomarker among a set of five (DNA ploidy, p53, EGF receptor, HER2/NEU, ER $\alpha$ ) that was significantly associated with the subsequent development of malignancy, although in the final multivariate model, only Gail risk and cytological atypia remained significant (Fabian et al. 2000).

In DL samples from high-risk women, we have encountered much higher levels of ER $\alpha$ positivity than we reported previously in the control groups of our earlier studies, with a median LI of $26 \%$, probably because we are using newer, more sensitive antibodies, and are studying high-risk women who may have higher proportions of ER-positive cells. So far, we have seen reassuring stability of ER expression over two time points 6 months apart, when the second sample is obtained in the same phase of the menstrual cycle as the first (Bhandare et al. 2003). Our on-going study will also provide information as to whether or not high $E R \alpha$ expression in benign or atypical epithelium identifies women more likely to benefit from endocrine prevention strategies.

\section{ER $\beta$}

The second estrogen receptor, ER $\beta$, was cloned in 1996, and has been intensively investigated regarding its role in normal mammary gland development and breast cancer (Kuiper et al. 1996, Gustafsson \& Warner 2000). Its relevance as a marker of risk, or as a surrogate endpoint in prevention studies is not clear as yet, but deserves investigation for several reasons, including the fact that it appears to influence activity of ER $\alpha$. Several studies on normal breast epithelium have revealed that ER $\beta$ is more abundant than ER $\alpha$ in the nuclei of epithelial cells lining the ducts and the lobules, and that a strong staining pattern is seen in myoepithelial cells, with varying intensity of staining documented in intralobular stromal cell nuclei, nuclei of endothelial cells and occasional lymphocytes (Speirs et al. 2002). ER $\beta$ is expressed in the majority of normal lobules, in contrast to ER $\alpha$ (median fraction of positive cells over $90 \%$ in one study, compared with $22.6 \%$ for ER $\alpha$ (Shaaban et al. 2003)). The proportion of positive cells decreases with increasing degrees of neoplasia, with a steady decrease in proliferative lesions, carcinoma in situ, and invasive disease (Roger et al. 2001). Thus the ratio of ER $\beta: E R \alpha$ measured at the mRNA level decreases from normal breast to breast cancer (Leygue et al. 1998).

Relative levels of ER $\alpha$ and ER $\beta$ are an important determinant of cellular sensitivity to estrogens. Although $\mathrm{ER} \alpha$ is the stronger transcriptional activator of the two, at physiological concentrations of estradiol, coexpression of ER $\beta$ results in suppression of both the efficacy and potency of hormone-stimulated responses. The ability of ER $\beta$ to function as a transcriptional activator or inhibitor, depending on the agonist concentration, suggests that completely different patterns of gene expression may be observed at different hormone levels (Hall \& McDonnell 1999). Such interactions may influence the action of potential preventive agents such as genistein (one of the major phytoestrogens in soy), which appears to have a greater affinity for ER $\beta$ than for ER $\alpha$ (Kuiper et al. 1997). This could indicate that phytoestrogens work as antioxidants and that ER $\beta$ is involved in the control of antioxidant-regulated genes, the products of which control the concentrations of free radicals and reactive oxygen species in the cell (Gustafsson 1999). 


\section{Proliferation and apoptosis in normal breast}

Normal breast epithelial proliferation has been extensively studied relative to the menstrual cycle, with general agreement that a rise in proliferative index occurs in the luteal phase (Meyer 1977, Anderson et al. 1982, Potten et al. 1988). This has been particularly well illustrated by studies of FNA in spontaneously cycling women who underwent FNA in the follicular and luteal phase, with ovulation being assessed by the measurement of serum progesterone (Soderqvist et al. 1997). A significant correlation was seen between serum progesterone values and $\mathrm{Ki}-67$ labeling, but none with serum estradiol, testosterone, androstenedione, or several peptide hormones. The use of OCs appears to increase breast epithelial proliferation (Anderson et al. 1989), a fact which needs to be reconciled with the fairly minimal impact of OC use on breast cancer risk (Westhoff 1999). In postmenopausal women, a significant relationship has been observed between the use of HRT and breast epithelial proliferation. In a study analyzing FNA samples prior to, and 3 and 6 months following the initiation of HRT in 45 postmenopausal women, Conner et al. (2003) found that the percentage of Ki-67-positive cells increased more than 4-fold after just 3 months of HRT. There was a positive correlation between percentage of Ki-67-positive breast cells and circulating levels of both estradiol and estrone after 3 and 6 months of treatment. In contrast, no increase in the proliferation index was seen in a cross-sectional study by Hargreaves et al. (1998) where biopsy material from women on HRT was compared with those not using it. These findings serve to emphasize the point that the variability of these measurements between individuals is significant, and that longitudinal, within-person comparisons are significantly more sensitive than cross-sectional study designs.

However, prospective evidence that cell proliferation indices in the normal epithelium and benign breast lesions may serve as a marker of breast cancer risk is still lacking, and there are no longitudinal studies demonstrating that the proliferative index of normal epithelium or proliferative lesions relates to breast cancer risk. Such studies are difficult to perform, since the proliferative index of breast epithelium is low, reproducible quantitation of proliferative indices in large numbers of samples is problematic, and in premenopausal women samples need to be acquired in a specific menstrual phase. These barriers have not so far been overcome in human studies. However, one study of ER $\alpha$ expression and proliferative indices of hyperplastic lesions in women who subsequently developed breast cancer, compared with those who did not, suggests that the Ki-67 labeling index (Ki-67 LI) is higher in the hyperplastic foci of women who later developed cancer (Shaaban et al. 2002). In this small study (27 cases and 16 controls), the cases and controls were not age-matched and although both $\mathrm{ER} \alpha$ and $\mathrm{Ki}-67$ are known to vary significantly with age in normal epithelium, the relationship to age in hyperplastic lesions has not been assessed. The OR was higher for ER $\alpha \mathrm{LI}(2.3,95 \% \mathrm{CI} 0.7-7.2)$ than for $\mathrm{Ki}$ 67 LI $(1.5,95 \%$ CI $0.5-5.8)$.

The measurement of proliferative activity as a potential surrogate endpoint biomarker in the assessment of preventive efficacy of new agents needs similar validation in long-term studies. Several studies of short-term neoadjuvant therapy in women with breast cancer have shown a significant decrease in the proliferative indices of malignant lesions with endocrine therapy, but this decrease was not independently predictive of response (Chang et al. 2000). In another study of 32 women without known breast cancer who were given letrozole treatment, estradiol levels dropped significantly, but there was no significant change in proliferative indices at 3 months (Harper-Wynne et al. 2002). The problems of utilizing Ki-67 labeling as a predictor of response are illustrated in a subsequent non-randomized study by the same group, where Ki-67 LI was examined as a predictor of response in 106 women with large breast cancers who were treated with tamoxifen, chemotherapy or a combination (Assersohn et al. 2003). Another group of 37 untreated women underwent two separate FNAs to assess the reproducibility of Ki-67 labeling; analysis of their proliferative indices suggested that a minimal relative decline of $39 \%$ was required for statistical significance. For the final analysis, the authors excluded women whose Ki-67 LI was under 5\% because of concerns regarding the precision of the measurement; this resulted in 20 of $33(61 \%)$ of the tamoxifen-treated group being excluded. In the chemoprevention setting then, where baseline proliferative indices tend to run around $2 \%$, the difficulties of utilizing $\mathrm{Ki}-67$ labeling as a surrogate biomarker seems significant. Data from ongoing studies should help resolve these questions.

Published data on proliferative indices in cytological samples of breast epithelium obtained by DL are not available so far, but again the hurdles discussed above with regard to the variability of measuring low frequency events would be compounded by the small samples available in such studies. We have found that the Ki-67 LI of DL samples has a median value of 
$0.3 \%$, measured in a median of 5690 cells. Whether or not this value is lower than that reported in FNA studies because exfoliated cells tend not to be proliferating, or for other reasons, is not clear at the moment, but trypan blue exclusion rates of these samples range from 50 to $90 \%$ (Khan et al., unpublished observations).

\section{Apoptosis in normal breast epithelium}

Apoptosis or programmed cell death plays a critical role in normal mammary gland development. Homeostasis in normal tissue is a balance of proliferation and apoptosis, and alteration in this balance has been postulated to set off a series of changes ultimately leading to malignancy (Thompson 1995). Morphologically, apoptotic cells exhibit characteristic changes such as cell contraction, cytoplasmic blebbing, nuclear condensation and genomic autodigestion into nucleosomal fragments. The measurement of apoptosis in the normal breast has been performed by the counting of apoptotic bodies on histological sections, by the TUNEL (TdT-mediated dUTP nick-end labeling) reaction, and more recently by IHC detection of activated caspase-3, which represents the final enzymatic event leading to DNA fragmentation (Gown \& Willingham 2002). There is agreement that a wave of apoptosis occurs in late luteal phase (Anderson et al. 1982, Williams et al. 1991), and that proliferative and apoptotic rates increase as epithelium progresses from normality to malignancy (Allan et al. 1992, Bai et al. 2001). Two studies of apoptosis and proliferation in normal breast epithelium from women with breast cancer and those undergoing benign breast biopsy for conditions such as fibroadenoma concluded that the ratio of proliferative to apoptotic indices is higher in women with breast cancer (Allan et al. 1992, Hassan \& Walker 1998), suggesting that decreased elimination of epithelial cells may contribute to the development of malignancy. However, as pointed out by Anderson (1999) in a review of the subject, parity, lactation, contraceptive use, and age of the two groups were not controlled for, and all of these factors are known to influence cell kinetics in the normal breast. In addition, the method of measurement of apoptosis deserves some comment. Allan et al. used classic morphological criteria, whereas Hassan \& Walker used a combination of in situ end-labeling and morphology. The apoptotic indices reported by these authors vary by an order of magnitude (0.1 to 1.2 ), compared with 0.3 reported in another study where morphology alone was used to identify apoptotic cells (Potten et al. 1988). Studies using TUNEL report values ranging from 0.0 (Bai et al. 2001) to 0.04 (Wong et al. 2001), to 2.1 per terminal duct lobular unit (Feuerhake et al. 2003). Using TUNEL, we have found values of $0.2 \%$ for premenopausal women, and $0.1 \%$ for postmenopausal women. Although we found no significant differences in median apoptosis and proliferative indices in breast cancer cases as opposed to benign disease controls, a multivariate model including TUNEL and $\mathrm{Ki}-67 \mathrm{LI}$, and menopausal status, yielded an OR of 3.66 (95\% CI 1.22-10.96) for the TUNEL index (Khan \& Stickles 2000). Another study of normal breast epithelium and usual ductal hyperplasia on women with long-term follow-up also showed no predictive value of these measures for the subsequent development of malignancy, although ratios were not calculated (Mommers et al. 2001). Thus, although there has been widespread recognition that the study of apoptosis in the normal breast and pre-malignant lesions is important, normal breast studies have been hampered by methodological discrepancies, and as in studies of proliferation, the quantitation of apoptosis in large numbers of samples remains a problem today. The fact that apoptotic rates in normal epithelium and benign lesions are even lower than proliferative rates is another barrier to the inclusion of this parameter as a surrogate endpoint biomarker in studies of risk and prevention.

\section{Inter-relationship between hormone response parameters in cytological samples}

The ability to measure breast hormone levels in NAF and duct lavage fluid, and relate these to the cellular parameters discussed above provides an opportunity to test the paradigm presented at the beginning of this review. Based on this paradigm, we would expect a hierarchical relationship between estrogenic hormones, the fraction of ER $\alpha$-positive cells, Ki-67 labeling, epithelial cell number and cytological atypia. We are presently conducting a study of high-risk women, where the DL effluent is separated into cells and supernatant, allowing analysis of both breast hormone levels and cellular parameters in the same samples. So far, we have been able to observe fragments of this hierarchy: hormonal parameters (particularly ES and DHEAS) relate significantly to cell number, and to cytological atypia; cell number and atypia are strongly inter-related, but the intermediary link with Ki-67 labeling is so far not evident. These women will be restudied after 6 months on tamoxifen therapy, and the same parameters re-examined, providing new data on the effects of tamoxifen on the endocrine environment and hormone responsiveness of the high-risk and normal breast. 


\section{Conclusions}

Of the estrogen-related endpoints that have been studied so far, the largest amount of data exists regarding ER $\alpha$ expression and proliferation. The former is an established therapeutic target, and may be of utility as a marker of risk and for selecting women for endocrine prevention strategies. The variability of the latter, at least as measured by Ki-67 labeling, is a significant concern and may ultimately prove to be a barrier to its utilization as a surrogate endpoint in prevention studies. The variability of apoptosis on repeat sampling has not been established, but the low proportion of apoptotic cells in breast epithelial samples, and the difficulties of quantitation related to this, makes it an unlikely surrogate endpoint. Additional studies are needed to establish the optimal menstrual cycle phase for breast epithelial sampling in premenopausal women, the variability of potential surrogate endpoints on repeat sampling in untreated women, and the variability of measurement of specific endpoints, particularly those that are present in small proportions of epithelial cells, such as proliferation and apoptosis. Additional work also needs to be done on the utility of nipple and duct fluid hormone concentrations, their reproducibility in untreated individuals, and their relationship to breast cancer risk. If validated, these are attractive candidates for intermediate biomarkers, particularly in studies of agents which modify local hormone synthesis in the breast.

\section{Acknowledgements}

The research work was supported by the Bluhm family Program for breast cancer early detection and prevention. The authors declare that there is no conflict of interest that would prejudice the impartiality of this work.

\section{References}

Allan DJ, Howell A, Roberts SA, Williams GT, Watson RJ, Coyne JD, Clarke RB, Laidlaw IJ \& Potten CS 1992

Reduction in apoptosis relative to mitosis in histologically normal epithelium accompanies fibrocystic change and carcinoma of the premenopausal human breast. Journal of Pathology 167 25-32.

Anderson TJ 1999 Pathological studies of apoptosis in the normal breast. Endocrine-Related Cancer 6 9-12.

Anderson TJ, Ferguson DJ \& Raab GM 1982 Cell turnover in the 'resting' human breast: influence of parity, contraceptive pill, age and laterality. British Journal of Cancer 46 376-382.
Anderson TJ, Battersby S, King RJB, McPherson K \& Going JJ 1989 Oral contraceptive use influences resting breast proliferation. Human Pathology 20 1139-1144.

Assersohn L, Salter J, Powles TJ, A’Hern R, Makris A, Gregory RK, Chang J \& Dowsett M 2003 Studies of the potential utility of Ki67 as a predictive molecular marker of clinical response in primary breast cancer. Breast Cancer Research and Treatment 82 113-123.

Bai M, Agnantis NJ, Kamina S, Demou A, Zagorianakou P, Katsaraki A \& Kanavaros P 2001 In vivo cell kinetics in breast carcinogenesis. Breast Cancer Research 3 276-283.

Battersby S, Robertson BJ, Anderson TJ, King RJB, McPherson K 1992 Influence of menstrual cycle, parity and oral contraceptive use on steroid hormone receptors in normal breast. British Journal of Cancer 4 601-607.

Bhandare D, Golewale N, Geiger AS, Nayar R, Chatterton RT \& Khan SA 2003 Estrogen related biomarkers and cellular atypia in ductal lavage (DL) samples from women at high risk for breast cancer. Breast Cancer Research and Treatment 82 S178.

Black MH, Magklara A, Obiezu C, Levesque MA, Sutherland DJ, Tindall DJ, Young CY, Sauter ER \& Dimandis EP 2000 Expression of a prostate-associated protein, human glandular kallikrein (hK2), in breast tumours and in normal breast secretions. British Journal of Cancer 82 361-367.

Blankenstein MA, van de Ven J, Maitimu-Smeele I, Donker GH, de Jong PC, Daroszewski J, Szymcza J, Milewicz A \& Thijssen JH 1999 Intratumoral levels of estrogens in breast cancer. Journal of Steroid Biochemistry and Molecular Biology 69 293-297.

Chang J, Powles TJ, Allred DC, Ashley SE, Makris A, Gregory RK, Osborne CK \& Dowsett M 2000 Prediction of clinical outcome from primary tamoxifen by expression of biologic markers in breast cancer patients. Clinical Cancer Research 6 616-621.

Chatterton RT Jr, Geiger AS, Gann PH \& Khan SA 2003 Formation of estrone and estradiol from estrone sulfate by normal breast parenchymal tissue. Journal of Steroid Biochemistry and Molecular Biology 86 159-166.

Chatterton RT Jr, Geiger AS, Khan SA, Helenowski IB, Jovanovic BD \& Gann PH 2004 Variation in estradiol, estradiol precursors, and estrogen-related products in nipple aspirate fluid from normal premenopausal women. Cancer Epidemiology, Biomarkers and Prevention 13 928-935.

Chatterton RT Jr, Geiger AS, Mateo ET, Helenowski IB \& Gann PH 2005 Hormone levels in nipple aspirate fluid (NAF) of pre- and post-menopausal women: effect of oral contraceptives and hormone replacement. Journal of Clinical Endocrinology and Metabolism 90 1686-1691.

Cheng G, Weihua Z, Warner M \& Gustafsson JA 2004 Estrogen receptors ER alpha and ER beta in proliferation in the rodent mammary gland. PNAS 101 3739-3746.

Clarke RB, Howell A, Potten CS \& Anderson E 1997 Dissociation between steroid receptor expression and cell proliferation in the human breast. Cancer Research 57 4987-4991. 
Cohen SM \& Ellwein L 1991 Genetic errors, cell proliferation, and carcinogenesis. Cancer Research $\mathbf{5 1}$ 6493-6505.

Conner P, Soderqvist G, Skoog L, Graser T, Walter F, Tani E, Carlstrom K \& von Schoultz B 2003 Breast cell proliferation in postmenopausal women during HRT evaluated through fine needle aspiration cytology. Breast Cancer Research and Treatments 78 159-165.

Ernster VL, Wrensch MR, Petrakis NL, King EB, Miike R, Murai J, Goodson WH III \& Siiteri PK 1987 Benign and malignant breast disease: initial study results of serum and breast fluid analyses of endogenous estrogens. Journal of the National Cancer Institute 79 949-960.

Fabian CJ, Zalles C, Kamel S, Zeiger S, Simon C \& Kimler BF 1997 Breast cytology and biomarkers obtained by random fine needle aspiration: use in risk assessment and early chemoprevention trials. Journal of Cellular Biochemistry. Supplement 28-29 101-110.

Fabian CJ, Kimler BF, Zalles CM, Klemp JR, Kamel S, Zeiger S \& Mayo MS 2000 Short-term breast cancer prediction by random periareolar fine-needle aspiration cytology and the Gail risk model. Journal of the National Cancer Institute 92 1217-1227.

Feherty P, Farrer-Brown G \& Kellie AE 1971 Oestradiol receptors in carcinoma and benign disease of the breast: an in vitro assay. British Journal of Cancer 25 697-710.

Ferguson DJ \& Anderson TJ 1981 Morphological evaluation of cell turnover in relation to the menstrual cycle in the 'resting' human breast. British Journal of Cancer 44 177-181.

Feuerhake F, Sigg W, Hofter EA, Uterberger P \& Welsch U 2003 Cell proliferation, apoptosis, and expression of Bcl-2 and Bax in non-lactating human breast epithelium in relation to the menstrual cycle and reproductive history. Breast Cancer Research and Treatments 77 37-48.

Gown AM \& Willingham MC 2002 Improved detection of apoptotic cells in archival paraffin sections: immunohistochemistry using antibodies to cleaved caspase 3. Journal of Histochemistry and Cytochemistry $\mathbf{5 0}$ 449-454.

Gustafsson JA 1999 Estrogen receptor beta - a new dimension in estrogen mechanism of action. Journal of Endocrinology 163 379-383.

Gustafsson JA \& Warner M 2000 Estrogen receptor beta in the breast: role in estrogen responsiveness and development of breast cancer. Journal of Steroid Biochemistry and Molecular Biology 74 245-248.

Hall JM \& McDonnell DP 1999 The estrogen receptor betaisoform (ERbeta) of the human estrogen receptor modulates ERalpha transcriptional activity and is a key regulator of the cellular response to estrogens and antiestrogens. Endocrinology 140 5566-5578.

Hankinson SE \& Hunter D 2002 Breast cancer. In Textbook of Cancer Epidemiology, pp. 301-399. Ed HO Adami. New York: Oxford University Press.

Hankinson SE, Willet WC, Manson JE, Colditz GA, Hunter DJ, Spiegelman D, Barbieri RL \& Speizer FE 1998
Plasma sex steroid hormone levels and risk of breast cancer in postmenopausal women. Journal of the National Cancer Institute 90 1292-1299.

Harding C, Osundeko O, Tetlow L, Faragher EB, Howell A \& Bundred NJ 2000 Hormonally-regulated proteins in breast secretions are markers of target organ sensitivity. British Journal of Cancer 82 354-360.

Hargreaves DF, Knox F, Swindell R, Potten CS \& Bundred NJ 1998 Epithelial proliferation and hormone receptor status in the normal post-menopausal breast and the effects of hormone replacement therapy. British Journal of Cancer 78 945-949.

Harper-Wynne C, Ross G, Sacks N, Salter J, Nasiri N, Iqbal J, A'Hern R \& Dowsett M 2002 Effect of the aromatase inhibitor letrozole on normal breast epithelial cell proliferation and metabolic indices in postmenopausal women: a pilot study for breast cancer prevention. Cancer Epidemiology, Biomarkers and Prevention 11 614-621.

Hassan HI \& Walker RA 1998 Decreased apoptosis in noninvolved tissue from cancer-containing breasts. Journal of Pathology 184 258-264.

Hernandez-Guzman FG, Higashiyama T, Osawa Y \& Ghosh D 2001 Purification, characterization and crystallization of human placental estrone/dehydroepiandrosterone sulfatase, a membrane-bound enzyme of the endoplasmic reticulum. Journal of Steroid Biochemistry and Molecular Biology 78 441-450.

Jacquemier JD, Rolland PH, Vague D, Lieutand R, Spitalier JM \& Martin PM 1982 Relationships between steroid receptor and epithelial cell proliferation in benign fibrocystic disease of the breast. Cancer 49 2534-2536.

Kabuto M, Akiba S, Stevens RG, Neriishi K \& Land CE 2000 A prospective study of estradiol and breast cancer in Japanese women. Cancer Epidemiology, Biomarkers and Prevention 9 575-579.

Khan SA \& Stickles S 2000 Cell proliferation and apoptosis in the normal breast epithelium of pre, peri, and postmenopausal women. In Hormonal Carcinogenesis, vol III, pp. 418-423. Eds JJ Li, JR Daling \& SA Li. New York: Springer-Verlag.

Khan SA, Rogers MAM, Obando JA \& Tamsen A 1994 Estrogen receptor expression of benign breast epithelium and its association with breast cancer. Cancer Research $\mathbf{5 4}$ 993-997.

Khan SA, Rogers MA, Khurana KK, Meguid MM \& Numann PJ 1998 Estrogen receptor expression in benign breast epithelium and breast cancer risk. Journal of the National Cancer Institute 90 37-42.

Khan SA, Sadeva A, Naim S, Meguid MM, Marx W, Simon H, Halverson JD \& Numann PJ 1999 The normal breast epithelium of women with breast cancer displays an aberrant response to estradiol. Cancer Epidemiology, Biomarkers and Prevention 8 867-872.

Khan SA, Yee KA, Kaplan C \& Siddiqui JF 2002 Estrogen receptor alpha expression in normal human breast 
epithelium is consistent over time. International Journal of Cancer 102 334-333.

King RJB 1993 Estrogen and progestin effects in human breast carcinogenesis. Breast Cancer Research and Treatment 27 3-15.

Kuiper GG, Enmark E, Pelto-Huikko M, Nilsson S \& Gustafsson JA 1996 Cloning of a novel receptor expressed in rat prostate and ovary. PNAS 93 5925-5930.

Kuiper GG, Carlsson B, Grandien K, Enmark E, Haggblad J, Nilsson S \& Gustafsson JA 1997 Comparison of the ligand binding specificity and transcript tissue distribution of estrogen receptors alpha and beta. Endocrinology 138 863-870.

Lawson JS, Field AS, Champion S, Tran D, Ishikura H \& Trichopoulos D 1999 Low oestrogen receptor alpha expression in normal breast tissue underlies low breast cancer incidence in Japan. Lancet 354 1787-1788.

Lawson JS, Field AS, Tran DD \& Houssami N 2001 Hormone replacement therapy use dramatically increases breast oestrogen receptor expression in obese postmenopausal women. Breast Cancer Research 3 342-345.

Lawson JS, Field AS, Tran DD, Killeen J, Maskarenic G, Ishikura H \& Trichopoulos D 2002 Breast cancer incidence and estrogen receptor alpha in normal mammary tissue - an epidemiologic study among Japanese women in Japan and Hawaii. International Journal of Cancer 97 685-687.

Leygue E, Dotzlaw H, Watson PH \& Murphy LC 1998 Altered estrogen receptor alpha and beta messenger RNA expression during human breast tumorigenesis. Cancer Research 58 3197-3201.

Meyer JS 1977 Cell proliferation in normal human breast ducts, fibroadenomas, and other ductal hyperplasias measured by nuclear labeling with tritiated thymidine. Effects of menstrual phase, age and oral contraceptive hormones. Human Pathology 8 67-81.

Mommers EC, Page DL, Dupont WD, Schuyler P, Leonhart AM, Baak JP, Meijer CJ \& van Diest PJ 2001 Prognostic value of morphometry in patients with normal breast tissue or usual ductal hyperplasia of the breast. International Journal of Cancer 95 282-285.

Pasqualini JR, Chetrite G \& Nestour EL 1996 Control and expression of oestrone sulphatase activities in human breast cancer. Journal of Endocrinology 150 S99-S105.

Pasqualini JR, Cortes-Prieto J, Chetrite G, Talbi M \& Ruiz A 1997 Concentrations of estrone, estradiol and their sulfates, and evaluation of sulfatase and aromatase activities in patients with breast adenoma. International Journal of Cancer 40 587-591.

Petersen OW, Hoyer PE \& van Deurs B 1987 Frequency and distribution of estrogen receptor positive cells in normal nonlactating human breast. Cancer Research $\mathbf{4 7}$ 5748-5751.

Petrakis NL, Wrensch MR, Ernster VL, Miike R, Murai J, Simberg N \& Siiteri PK 1987 Influence pregnancy and lactation on serum and breast fluid estrogen levels: implications for breast cancer risk. International Journal of Cancer 40 587-591.

Pike MC, Spicer DV, Dahmoush L \& Press MF 1993 Estrogens, progestogens, normal breast cell proliferation, and breast cancer risk. Epidemiologic Reviews 15 17-35.

Pizzagalli F, Varga Z, Huber RD, Folkers G, Meier PJ \& St Pierre MV 2003 Identification of steroid sulfate transport processes in the human mammary gland. Journal of Clinical Endocrinology and Metabolism 88 3902-3912.

Potten CS, Watson RJ, Williams GT, Tickle S, Roberts SA, Harris M \& Howell A 1988 The effect of age and menstrual cycle upon proliferative activity of the normal human breast. British Journal of Cancer $\mathbf{5 8}$ 163-170.

Purohit A, Singh A \& Reed MJ 1999 Regulation of steroid sulphatase and oestradiol 17 beta-hydroxysteroid dehydrogenase in breast cancer. Biochemical Society Transactions 27 323-327.

Ree AH, Landmark BF, Eskild W, Levy FO, Lahooti H, Jahnsen T, Aakvaag A \& Hansson V 1989 Autologous down-regulation of messenger ribonucleic acid and protein levels for estrogen receptors in MCF-7 cells: an inverse correlation to progesterone receptor levels. Endocrinology 124 2577-2583.

Ricketts D, Turnbull L, Ryall G, Bakhshi R, Rawson NSB, Gazet JC, Nolan C \& Coombes RC 1991 Estrogen and progesterone receptors in the normal female breast. Cancer Research 51 1817-1822.

Roger P, Sahla ME, Makela S, Gustafsson JA, Baldet P \& Rochefort H 2001 Decreased expression of estrogen receptor beta protein in proliferative preinvasive mammary tumors. Cancer Research 61 2537-2541.

Rose DP, Lahti H, Laakso K, Kettunen K \& Wynder EL 1986 Serum and breast duct fluid prolactin and estrogen levels in healthy Finnish and American women and patients with fibrocystic disease. Cancer 57 1550-1554.

Russo J, Ao X, Grill C and Russo IH 1999 Pattern of distribution of cells positive for estrogen receptor and progesterone receptor in relation to proliferating cells in the mammary gland. Breast Cancer Research and Treatment 53 217-227.

Saceda M, Lippman ME, Chambon P, Lindsey RL, Ponglikitmongkol M, Puente M \& Martin MB 1988 Regulation of the estrogen receptor in MCF-7 cells by estradiol. Molecular Endocrinology 21157-21162.

Sauter ER, Daly M, Linahan K, Ehya H, Engstrom PF, Bonney G, Ross EA, Yu H \& Diamandis E 1996 Prostatespecific antigen levels in nipple aspirate fluid correlate with breast cancer risk. Cancer Epidemiology, Biomarkers and Prevention 5 967-970.

Sauter ER, Babb J, Daly M, Engstrom PF, Ehya H, Malick J \& Diamandis E 1998 Prostate-specific antigen production in the female breast: association with progesterone. Cancer Epidemiology, Biomarkers and Prevention 7 315-320.

Sauter ER, Klein G, Wagner-Mann C \& Diamandis EP $2004 a$ Prostate-specific antigen expression in nipple 
aspirate fluid is associated with breast cancer risk. Cancer Detection and Prevention 28 27-31.

Sauter ER, Lininger J, Magklara A, Hewett JE, Diamandis EP $2004 b$ Association of kallikrein expression in nipple aspirate fluid with breast cancer risk. International Journal of Cancer 108 588-591.

Shaaban AM, Sloane JP, West CR \& Foster CS 2002 Breast cancer risk in usual ductal hyperplasia is defined by estrogen receptor-alpha and Ki-67 expression. American Journal of Pathology 160 597-604.

Shaaban AM, O’Neill PA, Davies MP, Sibson R, West CR, Smith PH \& Foster CS 2003 Declining estrogen receptorbeta expression defines malignant progression of human breast neoplasia. American Journal of Surgical Pathology 27 1502-1512.

Shoker BS, Jarvis C, Sibson DR, Walker C \& Sloane JP 1999 Oestrogen receptor expression in the normal and precancerous breast. Journal of Pathology 188 237-244.

Shoker BS, Jarvis C, Clarke RB, Anderson E, Munro C, Davies MP, Sibson DR \& Sloane JP 2000 Abnormal regulation of the oestrogen receptor in benign breast lesions. Journal of Clinical Pathology 53 778-783.

Soderqvist G, Isaksson E, von Schoultz B, Carlstrom K, Tani E \& Skoog L 1997 Proliferation of breast epithelial cells in healthy women during the menstrual cycle. American Journal of Obstetrics and Gynecology 176 123-128.

Speirs V, Skliris GP, Burdall SE \& Carder PJ 2002 Distinct expression patterns of ERalpha and ERbeta in normal human mammary gland. Journal of Clinical Pathology $\mathbf{5 5}$ 371-374.

Sturgeon SR, Potischman N, Malone KE, Dorgan JF, Daling J, Schairer C \& Brinton LA 2004 Serum levels of sex hormones and breast cancer risk in premenopausal women: a case-control study (USA). Cancer Causes and Control 15 45-53.

Thijssen JH, van Landeghem AA \& Poortman J 1986 Uptake and concentration of steroid hormones in mammary tissues. Annals of the New York Academy of Sciences 464 106-116.

Thomas HV, Reeves GK \& Key TJ 1997 Endogenous estrogen and postmenopausal breast cancer: a quantitative review. Cancer Causes and Control 8 922-928.
Thompson CB 1995 Apoptosis in the pathogenesis and treatment of disease. Science 267 1456-1462.

Toniolo PG, Levitz M, Zeleniuch-Jacquotte A, Banerjee S, Koenig KL, Shore RE, Strax P \& Pasternack B 1995 A prospective study of endogenous estrogen and breast cancer in postmenopausal women. Journal of the National Cancer Institute 87 190-197.

Trichopoulos D, Hsieh CC, MacMahon B, Lin TM, Lowe CR, Mirra AP, Ravnihar B, Salber EJ, Valaoras VG \& Yuasa S 1983 Age at any birth and breast cancer risk. International Journal of Cancer 31 701-704.

Vanderbilt JN, Miesfeld R, Maler BA, Yamamoto KR 1987 Intercellular receptor concentration limits glucocorticoid-dependent enhancer activity. Molecular Biology 1 68-74.

Webb P, Lopez GN, Greene GL, Baxter JD \& Kushner PJ 1992 The limits of the cellular capacity to mediate an estrogen response. Molecular Endocrinology 6 157-167.

Westhoff CL 1999 Breast cancer risk: perception versus reality. Contraception $5925 \mathrm{~S}-28 \mathrm{~S}$.

Willemsen R, Kroos M, Hoogeveen AT, van Dongen JM, Parenti G, van der Loos CM \& Reuser AJ 1988 Ultrastructural localization of steroid sulphatase in cultured human fibroblasts by immunocytochemistry: a comparative study with lysosomal enzymes and the mannose 6-phosphate receptor. Histochemistry Journal 20 41-51.

Williams G, Anderson E, Howell A, Watson R, Coyne J, Roberts SA \& Potten CS 1991 Oral contraceptives (OCP) use increases proliferation and decreases oestrogen receptor content of epithelial cells in the normal human breast. International Journal of Cancer $\mathbf{4 8}$ 206-210.

Wittliff JL, Hilf R, Brooks F, Savlov ED, Hall TC \& Orlando RA 1971 Specific estrogen-binding capacity of the cytoplasmic receptor in normal and neoplastic breast tissues of humans. Cancer Research 32 1983-1992.

Wong SC, Chan JK, Lee KC \& Hsiao WL 2001 Differential expression of p16/p21/p27 and cyclin D1/ D3, and their relationships to cell proliferation, apoptosis, and tumour progression in invasive ductal carcinoma of the breast. Journal of Pathology 194 $35-42$. 